Vol. 20, pp. 1767-1770, 1986 Printed in the U.S.A.
Pergamon Journals Ltd. All rights reserved

\title{
AN OSCILLATORY VARIATION OF THE HALF-WIDTH OF X-RAY DIFFRACTION-LINE PROFILES WITH FATIGUE CYCLING
}

\author{
Xalyani Vijayan, A.Mani, C.Balasingh and A.X..Singh \\ Materials Science Division \\ National Aeronautical Laboratory \\ sangalore 560 017, India.
}

(Received September 10, 1986)

\section{Introduction}

It is well known that the fatigue cycling of crystalline materials can lead to detectable changes in the. x-ray diffraction-line profiles. As the full width at half maximum (FWHM) can be more easily derived from the line profile than other parameters such as variance or the Fourier co-efficients. many investigators $(1-10)$ have studied the effect of fatigue cycling on the FWHM of the diffraction line. The studies pertaining to the effect of fatigue cycling on Fourier coeffients are limited $8,11,12)$. The results on steel(1-8), iron(3), aluminium(9,10), and silicon, gold and aluminium alloy(9) indicate that the $\left(b / b_{0}\right)$ versus $N$ curve (where $N$ is number of fatigue cycles, and $b_{0}$ and $b$ are the pwhis, respectively, for the specimen before and after N cycles) in general shows three distinct stages. Fig. 1 shows this curve for annealed specimen of aluminium when the measurements are made using cuK radiation, so that diffraction occurs, from the near-surface region. The use of more

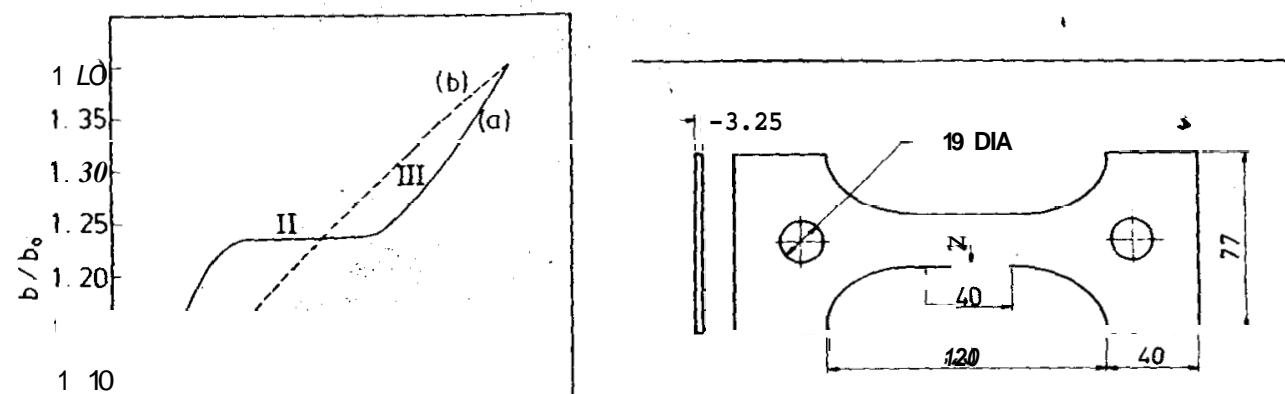

110

1.00 15

NüMIBER' OF FATIGUE CYCLES $\left(\mathrm{N} \times 10^{-5}\right)$

05

Fig. 1. (ía) A typical $\left(b / b_{0}\right)$ versus $N$ curve Ifor nituinition when the diffraction patterns

Fig.2. The dimensions of the specimen are recorded from the near-surface region of in $\mathrm{mm}$.

the specimen. The three stages are marked.

(b) The variation of $\left(\mathrm{b} / \mathrm{b}_{0}\right)$ with $N$ when penetrating radiation is used[9]. 
penetrating radiation (e.g. $M \circ K_{\text {a }}$ radiation) results in a linear variation (also shown in Fig.1) of (b/b) with $\mathrm{N}$.

In this note, we present the preliminary results on the measurement of FWHM on polycrystali ine aluminium specimens subjected to fatigue cycling, and report the observation of a hitherto unknown oscillatory variation of $\left(\mathrm{b} / \mathrm{b}_{0}\right)$ with $N$.

\section{Experimental Procedure}

The specimens used in this investigation were machined from $3.35 \mathrm{~mm}$ thick Alfax aluminium sheets of commercial purity 199.2 percent). The dimensions of the specimen are shown in Fig.2. The machined specimens were annealed at $160^{\circ} \mathrm{C}$ for one hour. The gauge sections of the specimens were hand polished with 600 grit emery and then electropolished for two- minutes at about $10^{\circ} \mathrm{C}$ using a mixture of 75 per cent methanol and 25 per cent nitric acid. These regions were used for all further x-ray measurements. Before comencing the fatigue cycling, back reflection $x$-ray patterns were recorded to ascertain that the specimens did not show pronounced texture.

The specimens were mounted on a specially designed jig which permitted simultaneous loading of two specimens. The fatigue cycling was conducted on Instron-1343 equipped with automatic servohydraulic load maintainer. The specimens were axially loaded in the tension-tension mode at constant stress amplitudes at $15 \mathrm{~Hz}$. The fatigue tests were carried out at three different stress amplitudes $(32,39$ and $46 \mathrm{MPa})$. The minimum load level was maintained at onetenth the maximum load.

The fatigue cycling was interrupted at intervals ranging from 2 to 5 per cent of the fatigue life of the specimens. At each interruption, the (422) diffraction line was recorded on a philips powder diffractometer using copper

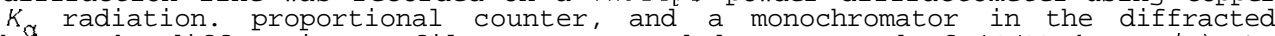
beam. The diffraction profiles were recorded at a speed of $(1 / 8)$ degree/minute and a chart speed of $20 \mathrm{~mm} / \mathrm{minute.}$

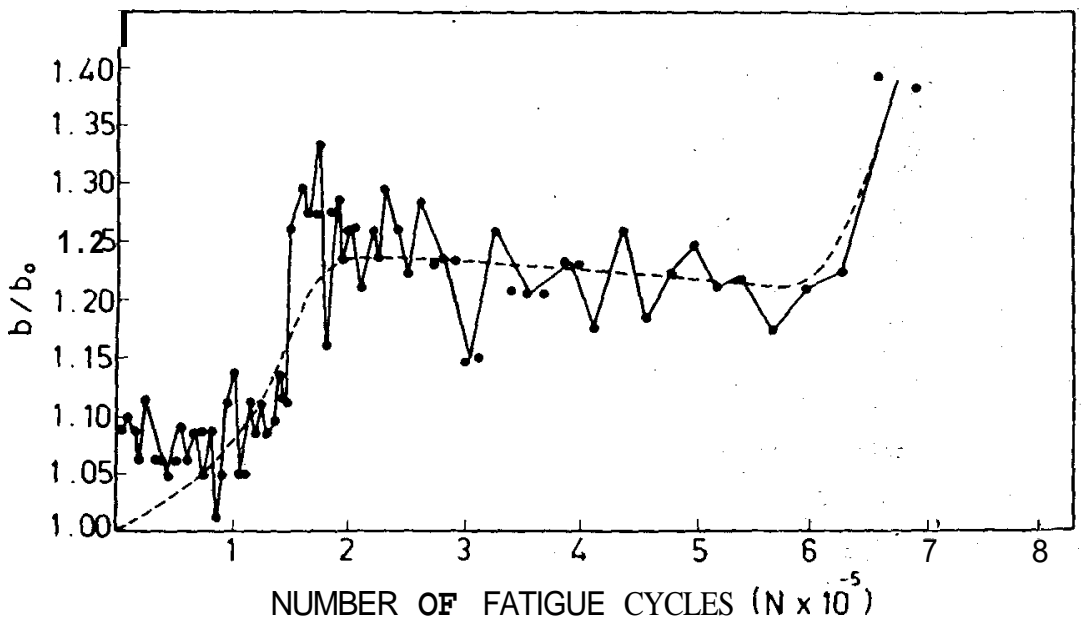

Fig.3. The $\left(b / b_{O}\right)$ versus $N$ data from the present experiment at $32 \mathrm{MPa}$.

The dashed line represents the average curve. 


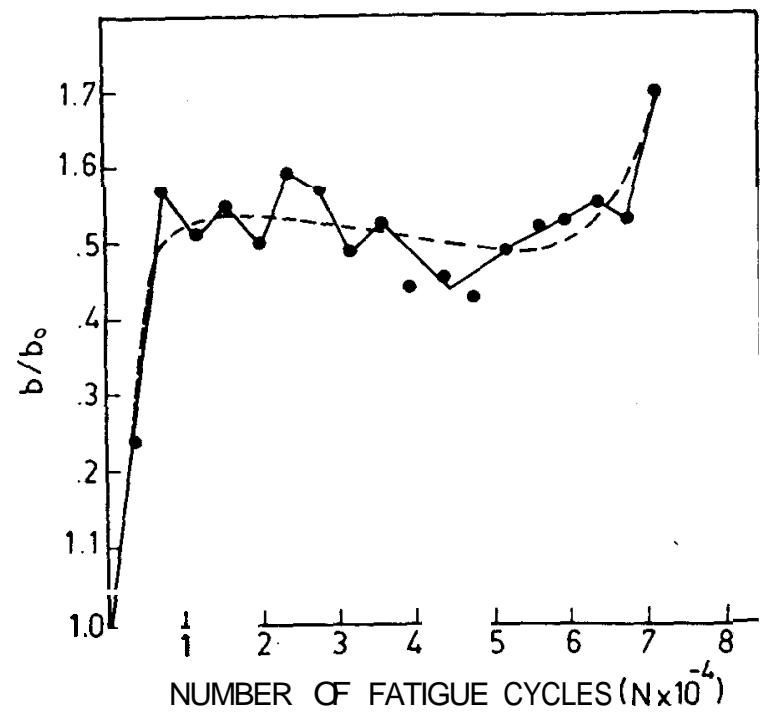

$\boldsymbol{F i g .}$, The $\left(\boldsymbol{b} / \boldsymbol{b}_{0}\right)$ versus $\mathrm{N}$ data from the present experiment at $46 \mathrm{MPa}$. The dashed line represents the average curve.

\section{Results and Discussion}

A typical set of $\left(b / b_{0}\right)$ versus $N$ data (stress amplitude 32 MPa) is shown in Fig.3. The estimated standard deviation, $\theta$, of FWHM measurement in the present experiments is 2 per cent of FWHM. The oscillatory curve shown in Fig.3 is obtained by joining the adjacent points by straight lines. If two or more adjacent points differ by less than $\sigma$, then these points are replaced by a single point at the mean position. Thus, the adjacent points joined by straight lines differ by at least a. The oscillatory nature of the (b/bo) versus $\mathrm{N}$ curve is clearly seen. The oscillatory nature persists even when the lines are drawn to join adjacent points differing by at least 30.

The present observation of the oscillatory nature of the (b/bo) versus $N$ data is to be compared with the three-stage curve (Fig.1) proposed by earlier investigators, to describe such data. It may be noted that if a few points are neglectedin the early stages of fatigue cycling, and a mean curve (shown by dotted Iines. in Fig.3) is drawn through the remaining points. then the resulting curve resembles closely the three-stage curve. This.suggests that oscillations could be described as the fine structure of a curve which, on an average, represents a three-stage curve. In order to detect the fine structure (osciliations), it is essential to gather ( $b / b_{0}$ ) versus $N$ data at close intervals which is of the order of 2 to 5 per cent of fatigue life. It is noticed that most of the $\left(' b / b_{o}\right)$ versus $N$ data reported in the literature so far, cogzespond to measurements at widely spaced intervals, and, therefore, lack the resolution required for the observation of the oscillations. The , observation of the oscillations in the present experiments is attributed primarily to. the choice of close intervals in $N$ for the measurement of FWHM.

The $\left(\boldsymbol{b} / \boldsymbol{b}_{\boldsymbol{o}}\right)$ versus $\mathrm{N}$ data obtained on specimens fatigue cycled at 46 MPa are shown in Fig.4. In this case also the oscillations with amplitudes well above the error.of measurements are clearly seen. The mean curve drawn through the points resembles closely a three-stage curve. 
The oscillations observed in the $\left(\mathbf{b} / \mathbf{b}_{0}\right)$ versus $\mathrm{N}$ data are found to exhibit the following characteristics:

(1) The oscillations start at the very early stages of fatigue cycling, and persist until the occurrence of the fatigue failure. The oscillations in the early stages of fatigue cycling are clearly seen in Fig.3. However, at highef stress amplitudes, (Fig, 4), the oscillations in the early stages were not seen because the intervals chosen for the measurements of FWHM were comparable to the entire span of stage $\boldsymbol{I}$.

(2) The oscillations are aperiodic. The lack of periodicity was ascertained by using a fast Fourier transform routine.

(3) The amplitudes of oscillations exhibit a wide range of variation. The highest observed amplitude is as large as 100.

\section{Ackinowileadgement}

The authors wish to thank R.sunder for the design of the loading jig and sustained guidance in conducting the fatigue tests, K.N.Raju for man helpful suggestions, and 0.S.Ramakrishna for running the fast Fourler transform routine.

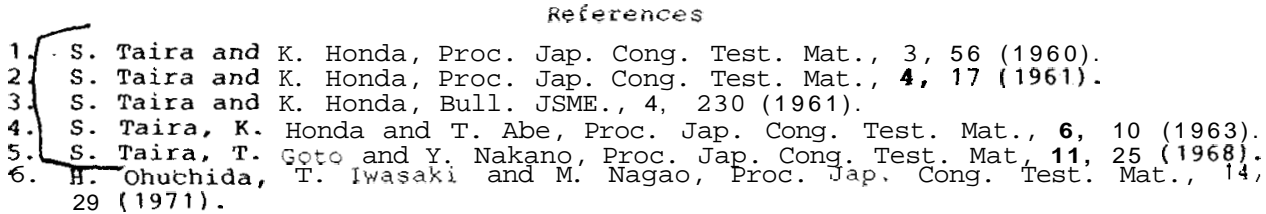

7. H. Takechi, K. Namba, K. Eujimara and K. Kawasaki, Trans. ISII., 21, $92(1981)$.

8. H. K. Kuo and J. B. Cohen, Mater. Sei. and Engg., 61, 127 (1983).

9. R. N. Pangborn, S. Weissman and I. R. Kramer, Met. Trans. 12A, 109 (1981).

10. M. ohomori, A. Himoto and T. Chiba, Proc. Jap. Cong. Test. Mat., 17, $61(1974)$.

11. R. W. Gould and C. F. gittella, Adv. Xray Anal., 16, 354 (1973).

12. R. G. Baggerly, R. M. N. Pelloux and W. F. Flanagan, Adv. Xray Anal., $10,329(1967)$. 